Archives

3| 1989

Varia

\title{
Rencontre franco-irlandaise. Marseille, 26 septembre - 2 octobre 1988
}

\section{Louis Cullen}

\section{(2) OpenEdition \\ Journals}

Édition électronique

URL : http://journals.openedition.org/ccrh/2935

DOI : $10.4000 /$ ccrh.2935

ISSN : $1760-7906$

Éditeur

Centre de recherches historiques - EHESS

Édition imprimée

Date de publication : 15 avril 1989

ISSN : 0990-9141

\section{Référence électronique}

Louis Cullen, «Rencontre franco-irlandaise. Marseille, 26 septembre - 2 octobre 1988 », Les Cahiers du

Centre de Recherches Historiques [En ligne], 3 | 1989, mis en ligne le 13 avril 2009, consulté le 01 mai 2019. URL : http://journals.openedition.org/ccrh/2935 ; DOI : 10.4000/ccrh.2935

Ce document a été généré automatiquement le 1 mai 2019.

Article L.111-1 du Code de la propriété intellectuelle. 


\title{
Rencontre franco-irlandaise. Marseille, 26 septembre - 2 octobre
}

\section{8}

\author{
Louis Cullen
}

1 Cette rencontre qui rassemblait des historiens français et irlandais s'est tenue à Marseille, à la Vieille Charité, du 28 septembre au 2 octobre 1988. Huit communications ont été présentées par des historiens irlandais, six par des historiens français. Deux autres historiens français sont ensuite intervenus comme commentateurs de certaines des communications françaises et irlandaises présentées dans les séances qu'ils présidaient.

2 Le thème de la rencontre était : « Culture et pratiques politiques en France et en Irlande $\mathrm{du} \mathrm{XVI}^{\mathrm{e}}$ au $\mathrm{XIX}^{\mathrm{e}}$ siècle ». Le choix de ce thème impliquait l'étude et l'identification des premières étapes de l'émergence d'une conscience politique au cours de cette période. En substance, il s'agissait d'une tentative de redéploiement des méthodes analytiques utilisées dans les dernières décennies en histoire économique et sociale, pour les appliquer à l'étude des changements intervenus dans la culture et les attitudes politiques qui ont précédé l'apparition d'une conscience politique moderne à différents moments, antérieurement au milieu du $\mathrm{XIX}^{\mathrm{e}}$ siècle. La rencontre de Marseille a été l'une des premières rencontres internationales à avoir proposé de mener cette recherche dans un cadre comparatif; l'objectif a été atteint grâce à quatorze communications couvrant l'histoire française et irlandaise $d u \mathrm{XVI}^{\mathrm{e}}$ au début du XIX siècle. Plusieurs d'entre elles se sont voulues explicitement comparatives. Cette tentative d'interprétation des témoignages confus qui concernent les premières manifestations de la conscience politique, se situe à trois niveaux différents : tout d'abord, une analyse très proche du détail, souvent très modeste en lui-même, qui, par récolement, acquiert une nouvelle signification ; deuxièmement, un examen minutieux des sources imprimées qui se prêtent à des interprétations autres que celles qui surgissent à l'occasion d'une lecture et d'une analyse fortuites ; troisièmement, l'application des méthodes utilisées en histoire sociale au cours des dernières décennies, aux structures politiques et aux manifestations d'un comportement politique. 
Ceci peut permettre d'apprécier l'activité politique et son évolution à une époque où les sources politiques des décennies ultérieures font largement défaut, et de parvenir à des conclusions pour une période où l'information politique se réduit en grande partie à des documents formels. Certaines communications avaient un contenu plutôt méthodologique (cf. R. Descimon, T. Dunne, A. Farge) ; d'autres ont proposé une analyse très large de tout un éventail de sources (cf. C. J. Caldicott, K. Whelan, R. Dupuy).

Les séances avaient été organisées autour de quatre thèmes: pouvoir et révolte; la politique et le peuple; la politique et ses représentations; les formes de la mobilisation politique. Il a été également proposé de poursuivre ces rencontres d'historiens, de part et d'autre. Louis Bergeron a indiqué qu'il ne lui paraissait pas souhaitable qu'un trop long intervalle sépare ces rencontres, comme ce fut le cas cette fois-ci. Il a également suggéré que les prochains débats se tiennent autour d'un thème industriel: par exemple, comparaison de la nourriture et de la boisson dans les deux pays. C'est en effet un thème qui offre de larges possibilités d'investigation et qui présentera probablement un grand intérêt, en particulier en ce qui concerne les tendances actuelles et prospectives.

\section{Introduction : Louis Bergeron et Alain Guéry}

\section{Pouvoir et révolte}

C.J. Caldicott (Department of French, University College, Dublin) :

The irish parliament and the Etats du Languedoc, 1642-1689: a comparative study of regional elites in office.

N. Canny (Department of History, University College, Galway) :

In defense of the constitution? The nature revolt in the seventeenth century.

P. Loupès (Université de Bordeaux III) :

Le jardin irlandais des supplices : la grande rébellion de 1641 vue à travers les pamphlets anglais.

\section{La politique et le peuple}

R. Descimon (Centre de recherches historiques, EHESS) :

Attitudes politiques et comportements civiques durant la Ligue parisienne.

C. Jouhaud (Centre de recherches historiques, EHESS) :

Le pouvoir baroque : de l'histoire de l'Etat à l'histoire des pratiques politiques.

D. Dickson (Department of modern History, Trinity College, Dublin) :

Centres of motion : irish cities and the origins of popular politics.

\section{La politique et ses représentations}

T. Bartlett (Department of History, University College, Galway) :

Militarisation and politicisation in Ireland.

R. Halevi (Centre de recherches historiques, EHESS) :

La politique révolutionnaire : le parti des monarchiens.

M. Elliott (Department of History, University of Liverpool) :

Wolfe Tone and the development of a revolutionay culture in Ireland. 


\section{Les formes de la mobilisation politique}

R. Dupuy (Université de Hautes-Bretagne, Rennes) :

Comportements politiques des contre-révolutionnaires dans l'Ouest: programme et stratégie (1793).

T. Dunne (Department of History, University College, Cork) :

The insecure voice : a catholic novelist in support of emancipation.

A. Farge (Centre de recherches historiques, EHESS) :

Les comportements populaires à Paris au XVIII ${ }^{\mathrm{e}}$ siècle : représentation sociale et politique.

K. Whelan (National Library, Dublin) :

The mobilisation of irish catholics, 1750-1850.

\section{AUTEUR}

\section{LOUIS CULLEN}

Louis CULLEN est professeur d'Histoire moderne à l'Université de Dublin, Trinity College. 